Research Article

\title{
Studies on Dry Sliding Wear and Solid Particle Erosive Wear Behaviours of Natural Fibre Composite Developed from Water Hyacinth Aquatic Plant for Automotive Application
}

\author{
A. Ajithram $\mathbb{D}^{1},{ }^{1}$ Jappes J. T. Winowlin $\mathbb{D}^{1},{ }^{1}$ Khan M. Adam $\mathbb{D}^{1},{ }^{1}$ N. C. Brintha $\mathbb{D}^{2}{ }^{2}$ \\ and Faris Waleed Fekry iD $^{3}$ \\ ${ }^{1}$ Department of Mechanical Engineering and Centre for Surface Engineering, Kalasalingam Academy of Research and Education, \\ Virudhunagar, Tamil Nadu, India \\ ${ }^{2}$ Department of Computer Science Engineering and Centre for Surface Engineering, \\ Kalasalingam Academy of Research and Education, Virudhunagar, Tamil Nadu, India \\ ${ }^{3}$ Department of Mechanical \& Aerospace Engineering, College of Engineering, International Islamic University Malaysia, \\ Gombak, Selangor, Malaysia
}

Correspondence should be addressed to Khan M. Adam; adamkhanm@gmail.com

Received 30 October 2021; Accepted 16 November 2021; Published 2 December 2021

Academic Editor: Veronica Calado

Copyright (c) 2021 A. Ajithram et al. This is an open access article distributed under the Creative Commons Attribution License, which permits unrestricted use, distribution, and reproduction in any medium, provided the original work is properly cited.

In this research, an attempt is made to investigate the abrasive and erosion wear resistance of aquatic waste plant water hyacinth converted fibre-reinforced polymer composites. From a novel approach, the new fibre extraction machine is designed to extract the hyacinth fibre from the parent plant and reinforce it to the epoxy matrix material to produce a natural fibre composite for frictional applications. The extracted fibre is dried in the open sunlight area for 22 to 35 days to remove moisture and external dust particles. Then, different weight percentages $(15,20,25,30$, and 35) of composite samples are produced with the help of the hot press compression moulding technique. Improved hyacinth composite tribology properties are tested by utilizing the pin on the disk machine. This setup included various processing parameters like load (10,20, and $30 \mathrm{~N})$, velocities $(1,2$, and $3 \mathrm{~m} / \mathrm{s})$, speed $(160,320$, and $479 \mathrm{rpm})$, and constant sliding distance condition, and the erosion setup also influences the essential parameters like impact angle $\left(30,45\right.$, and $\left.60^{\circ}\right)$, erodent velocity $(1,2.5$, and $3.3 \mathrm{~m} / \mathrm{s})$, and discharge rate $(28,41$, and $72 \mathrm{~g} / \mathrm{m})$. The factorial techniques are used to identify the important design factors. The final results represent the weight loss, volume loss, and erosion rate of hyacinth fibre composite. By utilizing the SEM (scanning electron microscope), the worn surface morphology of different weight percentages of hyacinth fibre samples are analysed. To upgrade the usage of hyacinth reinforced composites for different industrial applications, wear and erosion studies are conducted with different parameter conditions.

\section{Introduction}

In recent years, researchers are focusing on recycling of material concepts in the aspect of global impact because of environmental problems. Previously, in polymer composite fields, the synthetic fibres glass, carbon, and some of the other fibres were used. But all synthetic fibres have some disadvantages like being non-recyclable and non-degradable and having higher cost and high amount of energy consumption aspects. Nowadays, the demand for biodegradable materials is increasing [1]. Normally, the usage of natural fibres in the polymer composite material field has enormously increased and created a huge impact. All over the world, so many researchers and industrial experts used natural fibre as a reinforcement material because of so many positive advantages and applications compared to synthetic fibres. Generally, natural fibres have low cost and are biodegradable, very cheap, easily available, and ecofriendly. The natural fibre reinforced composites have very good mechanical strength and good thermal stability [2]. The sisal, coir, banana, hemp, jute, flax, and kenaf fibres are used as a reinforcement in the conventional polymer composites. The 
aspect of tribology behaviour in natural composites has not been properly covered and elaborated. These composite materials are used in building materials, commercial applications, and automotive and construction industries. Main disadvantage of natural fibre is the presence of external dust particles on the fibre surfaces, poor primary and secondary phase adhesions like reinforcement and matrix material phase, and dimensional stability [3]. However, composite developed with fibres and fillers as reinforcement in the matrix is the good combination for product development. Both natural and synthetic fibres have serious disadvantages [4]. Conventionally, fibres' primary phase and matrix material phase bonding is the main reason to increase and decrease the sample properties. But few surface treatments to the fibres slightly increase the bond between the reinforcement and matrix phase and this bonding surely expands the strength of the materials. From the interlocking bonding aspect, alkali treatment is one of the effective methods [5]. Based on the chemical structure and effect of the alkaline solutions, it dissolves the cellulose and hemicellulose contents on the surface of the fibre. This treatment increases the fibrillation process to remove the outer layer of the fibre. At the same time, the seawater treatment also improves the interfacial bonding of fibre composites. It leads to improving the mechanical property. In terms of tribology behaviours, most of the literature surveys cover the synthetic composite majorly. Fewer kinds of literature are only available to give the details in tribology behaviour of natural fibre composites. Generally, the BOR machine (block on ring) is used for the dry sliding test of the composite. The final results indicate the natural fibre's composite wear behaviour. Some of the authors studied and evaluated the natural fibre composite wear and erosion behaviours like sisal, coir, and palm fibre reinforced composite.

Mechanical degradation refers to solid particle erosion with the usage of different erodents [6]. Many industries reported material damages because of this erosion behaviour. Solid particle erosion is the conventional process to find out the progressive loss of a material's solid particles. Very few literature surveys are conducted in the aspect of natural fibre composite erosion studies. Mostly, the erosion rate of fibre composites is higher than that of the metals. The erosion behaviour is related to the velocity, impact angle, erodent type, and particle size parameters [7].

In this work, water hyacinth natural fibre is extracted from the parent plant and then the fibre is reinforced with epoxy matrix materials with different weight percentages, and a hyacinth fibre composite sample is produced with the help of a hot press compression moulding machine. Water hyacinth is a free-floating aquatic plant, mainly available in a local water body especially in a tropical and subtropical region [8]. Temperature plays a very important role in water hyacinth plant growth life. $15^{\circ} \mathrm{C}$ is the minimum, $20-28^{\circ} \mathrm{C}$ is an optimum level, and above $36^{\circ} \mathrm{C}$ is the maximum temperature of the water hyacinth plant [9]. The water hyacinth has a good character that it can grow fast over surface of any water bodies. So, even the Sun's rays will not penetrate below the water. The behaviour of the hyacinth plant is a serious threat to the entire environment [10]. All the countries invested huge amounts of money to remove hyacinth plants from the water bodies. Present work will encourage the researchers to use natural (waste) material as a useful material for effective utilization.

\section{Materials}

The water hyacinth plants are found in the water bodies of Trichy District, Tamil Nadu, India. After cultivating the plant, the separation process is done. The plant stem is separated from the parent plant. Normally, all the aquatic plant fibres are extracted by retting. Water hyacinth plant fibre cannot be effectively extracted from retting. By utilizing the mechanical way of the extraction process, hyacinth plant fibres are extracted. To remove the impurities and external dust particles, hyacinth fibres are cleaned by running water and distilled water. Then, the fibres are dried in the open sunlight area for 3 days until their colour turned from green to dark brown. This drying process is commonly used to remove the moisture content of the fibres. Epoxy resin is used as a matrix material with a combination of hardeners on a particular standard like LY556 and HY951 with a mixing ratio of $10: 1$ [11]. Table 1 explains the essential properties of hyacinth fibre and epoxy matrix materials. In a natural fibre composite, epoxy resin, which has high thermal stability, is mostly used as a matrix material to withstand the high temperature and enhance the mechanical properties of the reinforcement. These matrix materials were purchased from Covai Seenu \& Company, Coimbatore, Tamil Nadu, India. Figure 1 clearly describes the extraction process of water hyacinth plant fibres.

2.1. Fabrication of Composites. After the fibre extraction process is completed, different weight percentages of the composite sample are prepared $(15,20,25,30$, and $35 \%)$. Different weight percentages of fibre reinforcement are mixed with epoxy matrix material by using the compression moulding machine. In the hot press compression moulding machine, the upper plate temperature is set to $110^{\circ} \mathrm{C}$ and the lower plate temperature is $120^{\circ} \mathrm{C}$. Individual plate temperature is used to reducing the curing time of the composite sample. After the particular temperature is fixed on both plates, 1500PSI hydraulic pressure is applied to both the top and bottom plates. The time for curing and compression loading, for a proposed $300 \times 125 \times 3 \mathrm{~mm}$ composite plate, is fixed as 30 minutes. Figure 2 clearly explains the fabrication process of hyacinth reinforced fibre composites.

2.2. Wear Test Apparatus. The pin on disc (POD) testing machine is used to examine the water hyacinth fibre composite's dry sliding behaviour [12]. Easy availability, low cost, and quick handling methods are the reasons to use this apparatus commonly in the polymer matrix composites for wear applications. Initial verifications and surface preparation on disc material are carried out in advance to the experimentation [13]. Very thin and sharp brushes are used to clean the composite samples before and after the tests. Figure 3 shows the pin on disc apparatus. 
TABLE 1: Mechanical properties of epoxy resin and water hyacinth plant fibre.

\begin{tabular}{lcc}
\hline Properties & Epoxy resin & Water hyacinth fibre \\
\hline Density $\left(\mathrm{g} / \mathrm{cm}^{3}\right)$ & 1.12 & 1.02 \\
Tensile strength $(\mathrm{MPa})$ & 34 & 3.15 \\
Tensile modulus $(\mathrm{GPa})$ & 3.4 & 1.8 \\
Elongation $(\%)$ & 2.24 & 3.7 \\
\hline
\end{tabular}

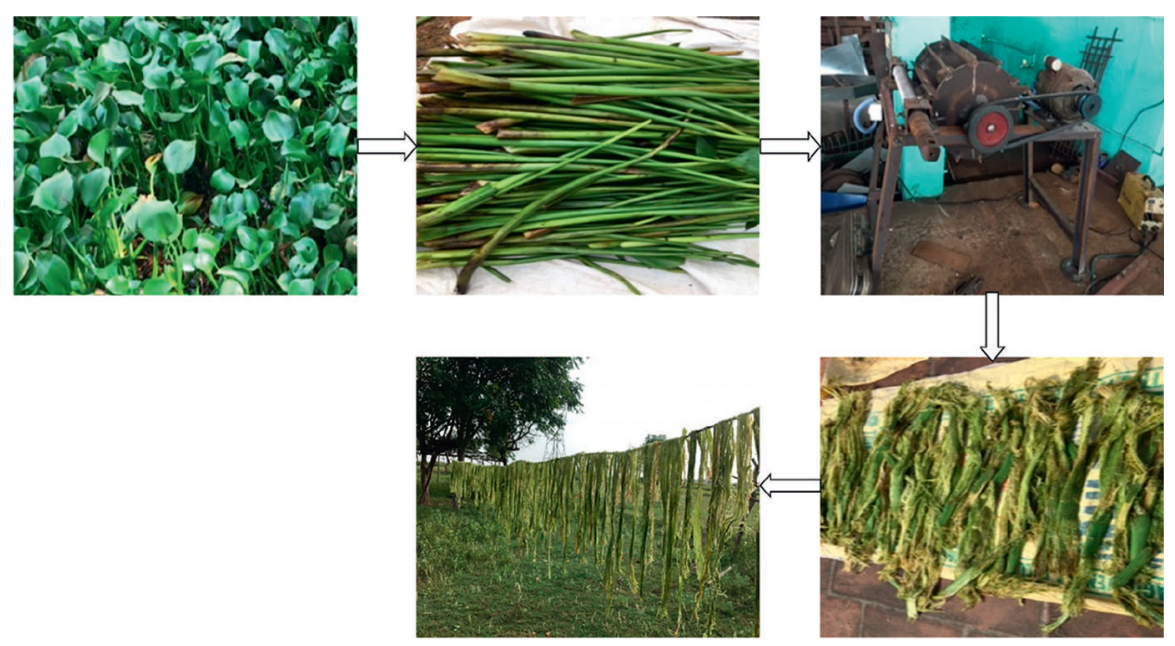

Figure 1: Extraction process of water hyacinth plant fibres.

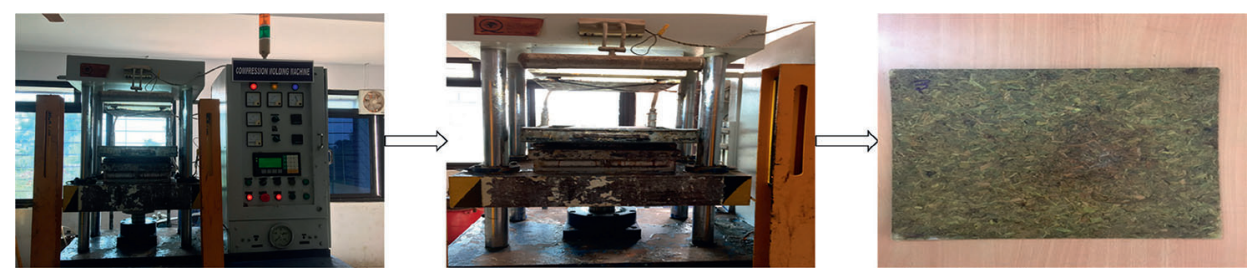

Figure 2: Fabrication process of water hyacinth plant fibre composite.

Once the wear test is finished, the average roughness of the sample is calculated with a different region. Volume loss of the natural fibre composite wear specimen is the measure before and after testing by utilizing an electronic weight balance machine $[14,15]$. The initial weight is assigned as $\mathrm{W} 1$, the final weight is assigned as $\mathrm{W} 2$, then the volume loss is measured, and five readings are taken in each samples for confirmation. Volume loss is calculated by using the following equation:

$$
\mathrm{VL}=\frac{\nabla w}{\rho} .
$$

2.3. Erosion Apparatus and Experimental Procedure. Water hyacinth natural fibre composite sample is tested with the DUCOM TR470 model erosion wear tester with a nozzle diameter of $1.5 \mathrm{~mm} .20-35 \mu \mathrm{m}$ alumina powder is used as the erodent material. The composite test samples are cut as per ASTM standards (G76 (2013)) with the dimension of $25 \times 25 \times 3 \mathrm{~mm}$ [16]. Figure 4 shows the air jet erosion test apparatus.
Before conducting the experiment, the sample is fully cleaned by pressurised air and dry cloth. The output response is measured in $\mathrm{g} / \mathrm{min}$. The erodent rate is governed by following equation:

$$
\mathrm{Er}=\frac{W_{b}-W_{a}}{t}
$$

Impinged surface hardness is measured by utilizing the micro Vickers hardness test. From the different impact regions, the five observations are taken for the calculations [17]. Density of the natural fibre composite is tested with the help of the Archimedes principle. The composite samples' theoretical density and experimental density are also measured [18].

2.4. Experimental Design. The combination of the output result process of dry sliding wear and erosive wear is determined by utilizing the design of the experiment method [19]. Normally, the full factorial technique is used to find the effect of different factors with $n$ levels. This experiment method was used as sequence operation to find out the minimum amount of wear and erosion of the sample. In a full factorial method, the 


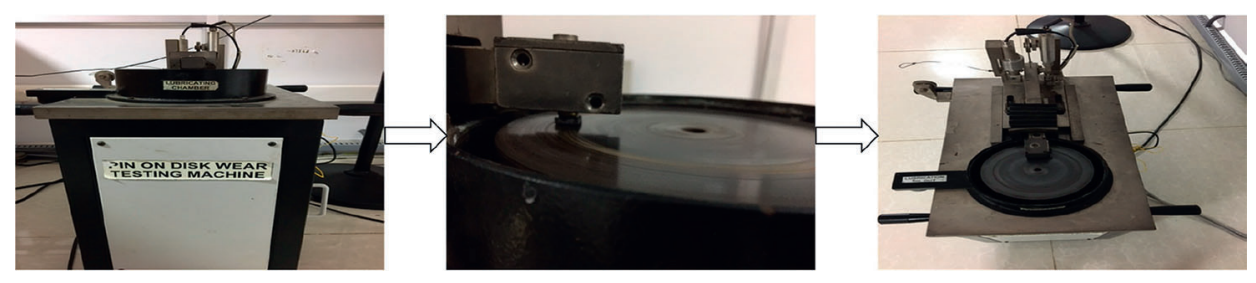

Figure 3: Pin on disc machine under the specimen test.

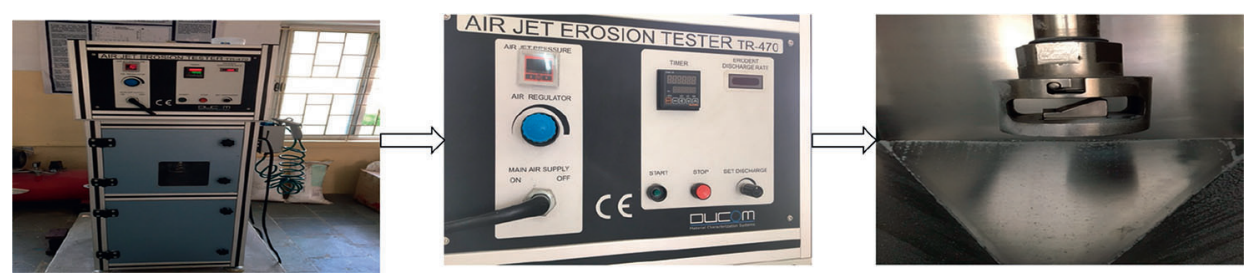

Figure 4: Air jet erosion test apparatus.

output response is involved in all combinations of the factor levels [20]. In dry sliding wear, the three factors applied load (A), sliding time (B), and sliding speed (C) are in control. Similarly, impact angle (A), particle velocity (B), and erodent discharge rate $(\mathrm{C})$ are the factors used to design the erosion experiments. Tables 2 indicates the control factors and level for dry sliding wear used in water hyacinth composite material. Table 3 indicates the control factors and level for erosive wear used in water hyacinth composite material.

2.5. Morphological Analysis. The morphological studies in worn surface of the composite is revealed with scanning electron microscope. Ziess SEM is used to capture highresolution images following standard working conditions.

\section{Result and Discussion}

3.1. Volume Loss. When using natural fibre as a reinforcement of the polymer matrix composites, the tribology properties are increased. This work briefly discussed the most influencing process parameters to get the minimum amount of wear like weight loss and volume loss. Increase in load at a maximum has highly influenced the material to reach maximum wear rate, and the same has been proved with existing literatures. The Taguchi orthogonal array experiments are based on the full factorial technique. By using the factorial technique, sliding speed, load, and influencing time parameters are determined. In this dry sliding experiment, the above three parameters are the most effective parameters. A dry sliding technique is used to determine the main effect, interaction effects, and their plots. Wear resistance of the water hyacinth-based composite is improved in some conditioning parameters. Epoxy matrix material resin easily penetrates the hyacinth fibre reinforcement, and it leads to strong interlocking. This dry sliding experiment decreased the interlocking property of the reinforcement and matrix material of the composite sample. Tables 4 and 5 describe the experimental design and its observation made through analysis of variance [21].
The expoxy material plays a vital role in increasing the mechanical strength and bonding of natural (bio) fibre. But a higher amount of fibre content decreases the mechanical property and internal bonding of the two states. Based on the experimentation, the wear rate varies with respect to increase in fibre weight percentage. Therefore, it has been confirmed that $30 \%$ (wt.) has good wear resistance compared to other combination. Conventionally, when a higher load acts for a long time, it leads to wear because a particular amount of heat is generated at the surface of the matrix and fibre reinforced sample. Figure 5 shows the main effect plots of the dry sliding output means and SN ratios of the hyacinth fibre sample.

However, the material removal rate is higher, and it leads to the weight loss and volume loss of the composite sample. From the literature surveys, compared to the other natural fibres, water hyacinth fibre with epoxy-based composite gives a positive effect on the test samples. Figure 6 clearly shows the residual plots for the dry siding output with respect to the frequency and standard residual.

3.2. Wear Mechanism. In general, the wear process takes place on the counter-face of the disc and the mating surface of the pin. Several types of plateaus have been formed. Generally speaking, plateaus are divided into two phases: dusty plateaus and rough plateaus. In the tribology system, the friction film affects the tribology performance. In the initial sliding process of the epoxy polymer composites reinforced with hyacinth natural fibres, debris in the form of fibre-matrix bulk found removed from the composite due to sliding friction following the pullout mechanism. There is evidence of fibre trapping near the sliding surface of the disc and in the friction layer. A dry sliding wear system's frictional layer is the layer that is most affected by the tribology performance of the pin on the disc. The frictional layer detaches from the machine surface when the load parameters are high. There is a high rate of material removal from the final debris and fragments, which attach to the disc with a friction layer. Due to the high friction, the film transferred smoothly during the test. It is apparent from this smooth transfer that the material has the least friction. A high volume loss at the test site is also one of the reasons for the loss. 
TABle 2: Control factors and levels for dry sliding wear test.

\begin{tabular}{lcccc}
\hline \multirow{2}{*}{ Factors } & \multicolumn{2}{c}{ Levels } & II & III \\
\hline Load (N) & I & 10 & 20 & 30 \\
Time (s) & 20 & 10 & 7 \\
Speed (rpm) & 160 & 320 & 479 \\
\hline
\end{tabular}

TABle 3: Control factors and levels for air jet erosion test.

\begin{tabular}{lccccc}
\hline Machining parameters & & Symbol & & Levels & Time \\
\hline Impact angle (degree) & IA & 30 & 45 & 60 & 10 \\
Discharge (g/min) & EV & 1 & 2.5 & 3.3 & 10 \\
Erodent velocity $(\mathrm{m} / \mathrm{s})$ & DR & 28 & 41 & 72 & 10 \\
\hline
\end{tabular}

TABle 4: Experimental observation for dry sliding wear test.

\begin{tabular}{|c|c|c|c|c|}
\hline S. No. & Load $(\mathrm{N})$ & Time $(\mathrm{t})$ & Speed (rpm) & Output \\
\hline 1 & 10 & 20 & 160 & 0.00160 \\
\hline 2 & 10 & 20 & 320 & 0.00220 \\
\hline 3 & 10 & 20 & 479 & 0.00280 \\
\hline 4 & 10 & 10 & 160 & 0.00150 \\
\hline 5 & 10 & 10 & 320 & 0.00290 \\
\hline 6 & 10 & 10 & 479 & 0.00340 \\
\hline 7 & 10 & 7 & 160 & 0.00170 \\
\hline 8 & 10 & 7 & 320 & 0.00260 \\
\hline 9 & 10 & 7 & 479 & 0.00370 \\
\hline 10 & 20 & 20 & 160 & 0.00150 \\
\hline 11 & 20 & 20 & 320 & 0.00240 \\
\hline 12 & 20 & 20 & 479 & 0.00450 \\
\hline 13 & 20 & 10 & 160 & 0.00250 \\
\hline 14 & 20 & 10 & 320 & 0.00340 \\
\hline 15 & 20 & 10 & 479 & 0.00520 \\
\hline 16 & 20 & 7 & 160 & 0.00360 \\
\hline 17 & 20 & 7 & 320 & 0.00420 \\
\hline 18 & 20 & 7 & 479 & 0.00640 \\
\hline 19 & 30 & 20 & 160 & 0.00624 \\
\hline 20 & 30 & 20 & 320 & 0.00790 \\
\hline 21 & 30 & 20 & 479 & 0.00856 \\
\hline 22 & 30 & 10 & 160 & 0.00290 \\
\hline 23 & 30 & 10 & 320 & 0.00370 \\
\hline 24 & 30 & 10 & 479 & 0.00460 \\
\hline 25 & 30 & 7 & 160 & 0.00290 \\
\hline 26 & 30 & 7 & 320 & 0.00260 \\
\hline 27 & 30 & 7 & 479 & 0.00340 \\
\hline
\end{tabular}

3.3. Erosive Wear. From the air jet erosion, the responses on the individual process parameters are discussed in detail. To recognize the effect of individual parameters, the graph is prepared by one parameter that is constant over another. Increasing the discharge rate (DR) leads to a higher erosion of the test samples [22]. At a 90-degree angle, the erodent strikes the surface of the material with respect to impact velocity. After impingement, the behaviour particle varies with respect to counter material. On the soft matrix, the material clings, and hard surface erodes fracture. This reacts with the responses on the surface. In addition, the erodent velocity will influence the response of wear rate. Tables 6 and 7 explain the experimental and analysis of variance observation of WH sample erosion test. Figure 7 indicates the mean effect plots of output and $\mathrm{SN}$ ratios on WH composite erosion test.

At 45 degrees, the particle slides at a maximum velocity, and shear rate increases. It has maximum material removal compared to other impact angle [23]. Figure 8 clearly indicates the normal probability plots and histogram plots of the hyacinth fibre composite erosion test with respect to the frequency and standard residual. 
TABLE 5: Analysis of variance observation.

\begin{tabular}{lccccccc}
\hline Source & DF & Seq SS & Adj SS & Ads MS & $F$ & $P$ & Contribution (\%) \\
\hline Load & 2 & 0.000045 & 0.000045 & 0.0000015 & 12.37 & 0.002 & 26.33 \\
Time & 2 & 0.000023 & 0.000023 & 0.000023 & 1.79 & 0.194 & 0.005 \\
Speed & 2 & 0.000003 & 0.000003 & 0.000003 & 9.73 & & 20.76 \\
Error & 20 & 0.000043 & 0.000043 & 0.000002 & & & \\
Total & 26 & 0.000088 & & & & \\
\hline
\end{tabular}
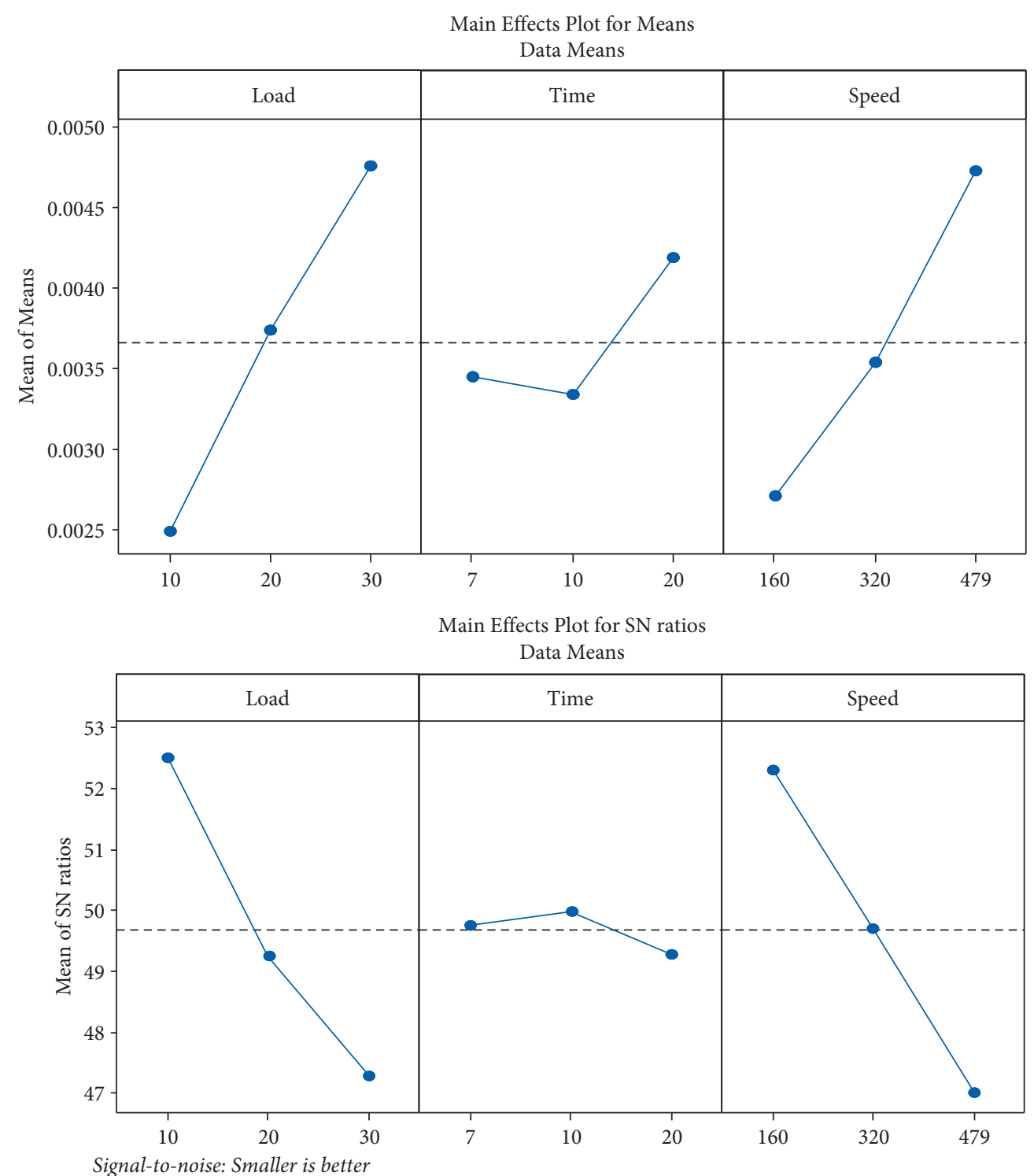

FIGURE 5: Main effect plots for means and SN ratios.

3.4. Erosive Wear Mechanism. Water hyacinth composite samples are evaluated through erosive wear with an air jet erosion machine. There is a high rate of wax discharge, which leads to erosive wear. It is the double erosion rate that takes up half of the erodent velocity increment. Our work focuses on determining the erosion rate of the hyacinth composite sample based on erosion rate parameters such as erodent velocity, impact angle, and discharge rate. In addition to a range of impact angles $\left(30^{\circ}, 45^{\circ}\right.$, and $\left.60^{\circ}\right)$, erodent velocity varies $(28,41$, and 72$)$ and the discharge rate lies in the range of $(1,2.5$, and 3.3).

3.5. Surface Morphological Studies. The wear morphology of the worn surface is studied with scanning electron microscope for different process parameters. It is clear to confirm that the common wear mechanism such as pullouts, fibre buckling, fracture in matrix material, phase debonding, and 

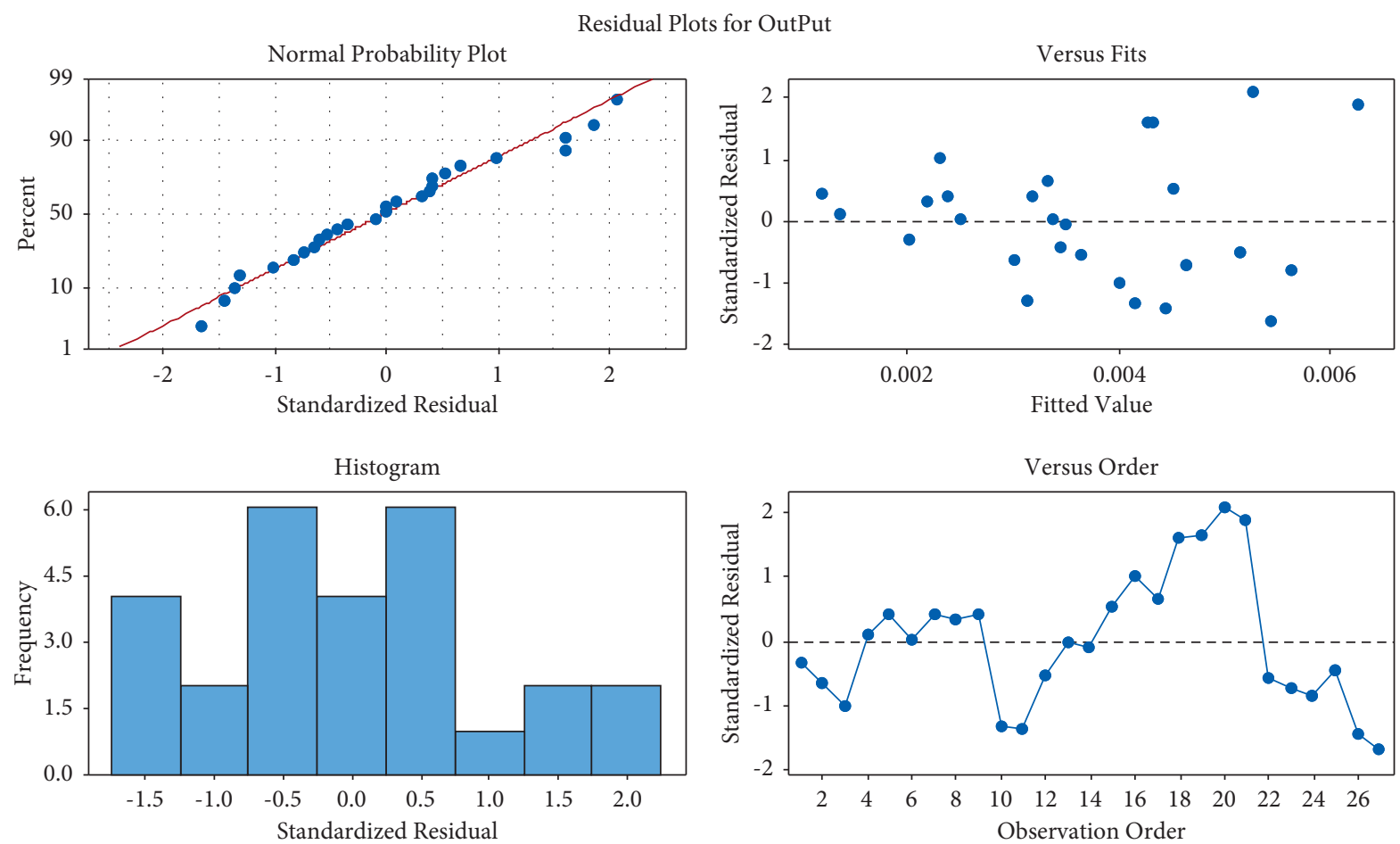

Figure 6: Residual plot output on dry sliding wear test.

TABLE 6: Experimental observation for air jet erosion test.

\begin{tabular}{|c|c|c|c|c|}
\hline S. No. & IA (degree) & $\mathrm{EV}(\mathrm{m} / \mathrm{s})$ & DR $(\mathrm{g} / \mathrm{min})$ & $E_{\mathrm{r}} 10^{-3}(\mathrm{~g} / \mathrm{min})$ \\
\hline 1 & 30 & 28 & 1 & 8.214 \\
\hline 2 & 30 & 28 & 2.5 & 6.324 \\
\hline 3 & 30 & 28 & 3.3 & 3.625 \\
\hline 4 & 30 & 41 & 1 & 11.452 \\
\hline 5 & 30 & 41 & 2.5 & 9.625 \\
\hline 6 & 30 & 41 & 3.3 & 8.540 \\
\hline 7 & 30 & 72 & 1 & 16.420 \\
\hline 8 & 30 & 72 & 2.5 & 13.480 \\
\hline 9 & 30 & 72 & 3.3 & 10.980 \\
\hline 10 & 45 & 28 & 1 & 6.470 \\
\hline 11 & 45 & 28 & 2.5 & 5.780 \\
\hline 12 & 45 & 28 & 3.3 & 4.162 \\
\hline 13 & 45 & 41 & 1 & 9.320 \\
\hline 14 & 45 & 41 & 2.5 & 7.520 \\
\hline 15 & 45 & 41 & 3.3 & 5.300 \\
\hline 16 & 45 & 72 & 1 & 13.490 \\
\hline 17 & 45 & 72 & 2.5 & 11.460 \\
\hline 18 & 45 & 72 & 3.3 & 9.640 \\
\hline 19 & 60 & 28 & 1 & 7.870 \\
\hline 20 & 60 & 28 & 2.5 & 3.640 \\
\hline 21 & 60 & 28 & 3.3 & 3.410 \\
\hline 22 & 60 & 41 & 1 & 8.590 \\
\hline 23 & 60 & 41 & 2.5 & 7.625 \\
\hline 24 & 60 & 41 & 3.3 & 6.320 \\
\hline 25 & 60 & 72 & 1 & 9.650 \\
\hline 26 & 60 & 72 & 2.5 & 9.640 \\
\hline 27 & 60 & 72 & 3.3 & 8.140 \\
\hline
\end{tabular}


TABLE 7: Analysis of variance observation.

\begin{tabular}{|c|c|c|c|c|c|c|}
\hline Source & DF & Seq SS & Adj SS & Ads MS & $F$ & Contribution (\%) \\
\hline IA & 2 & 31.535 & 0.108 & 0.1077 & 0.11 & 11.79 \\
\hline $\mathrm{EV}$ & 2 & 153.258 & 26.330 & 26.3297 & 27.89 & 57.32 \\
\hline DR & 2 & 53.292 & 7.191 & 7.1911 & 7.62 & 19.93 \\
\hline $\mathrm{IA} \times \mathrm{EV}$ & 4 & 8.796 & 8.716 & 8.7165 & 9.23 & 3.26 \\
\hline $\mathrm{IA} \times \mathrm{DR}$ & 4 & 1.691 & 1.691 & 1.6911 & 1.79 & 0.63 \\
\hline $\mathrm{EV} \times \mathrm{DR}$ & 4 & 0.007 & 0.007 & 0.0065 & 0.01 & 0.00 \\
\hline Error & 8 & 18.878 & 18.878 & & & \\
\hline Total & 26 & 267.377 & & & & \\
\hline
\end{tabular}
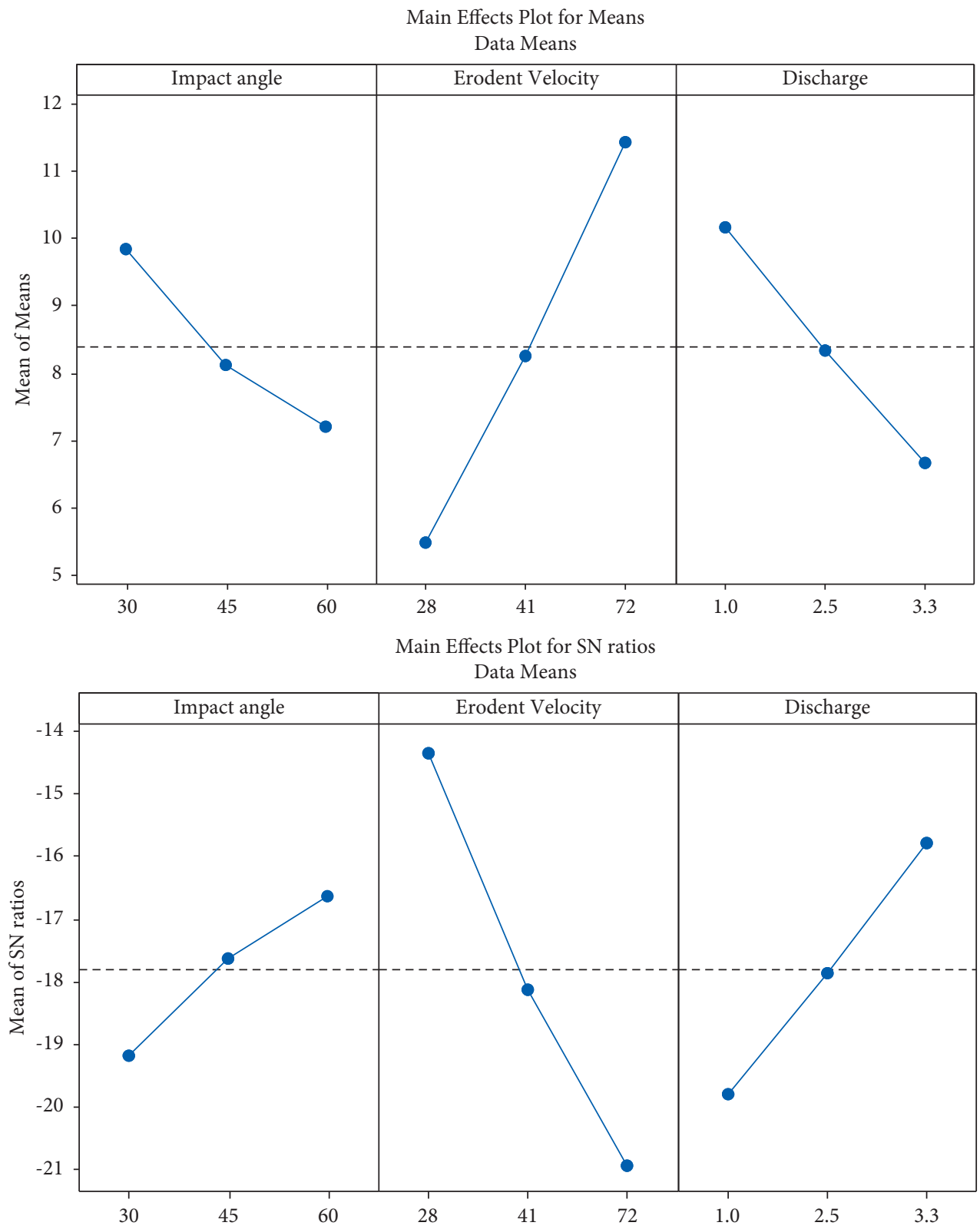

Signal-to-noise: Smaller is better

FIgURe 7: Main effect plots for means and SN ratios. 

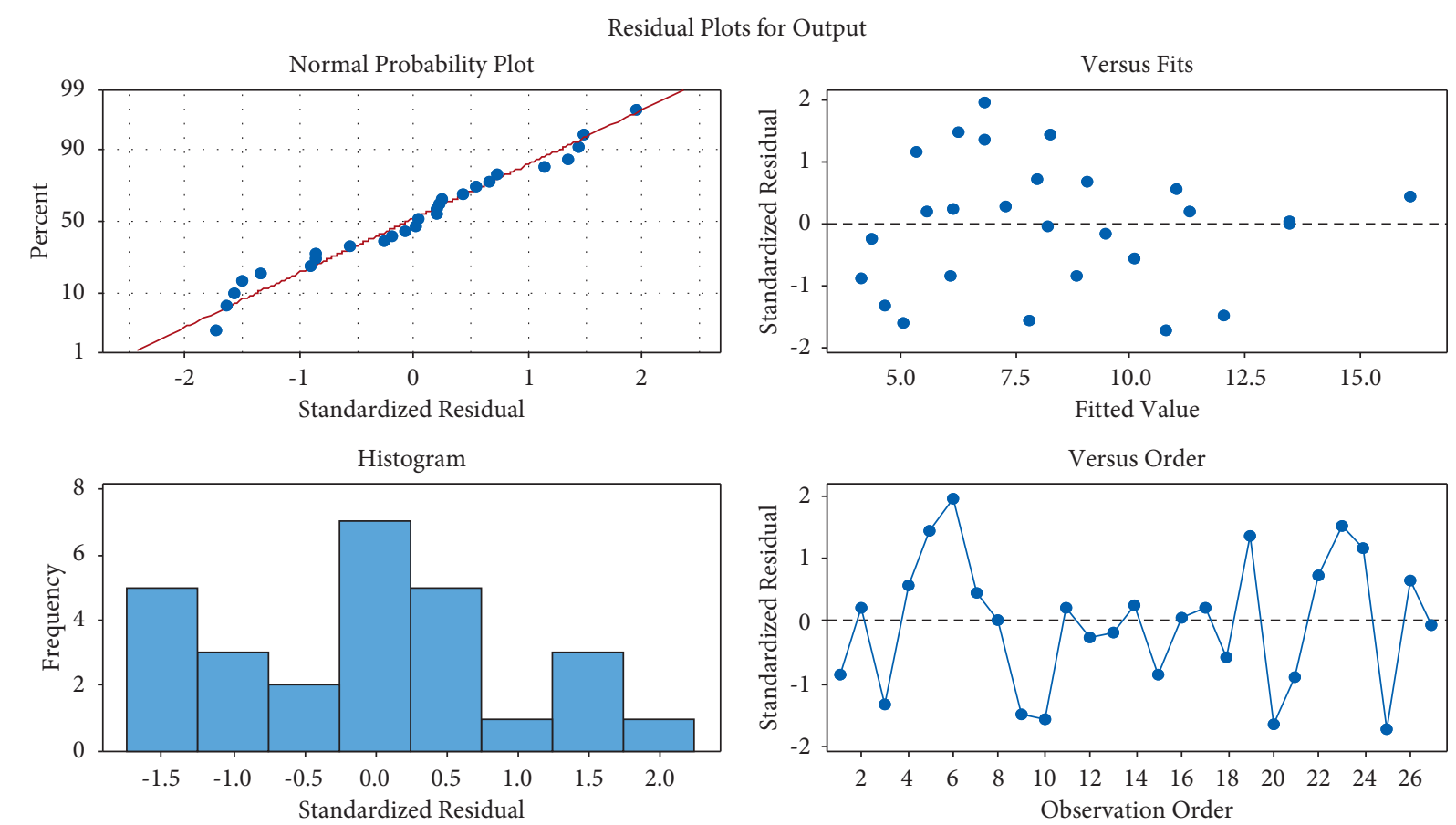

FIgURE 8: Residual plot output on dry sliding wear test.

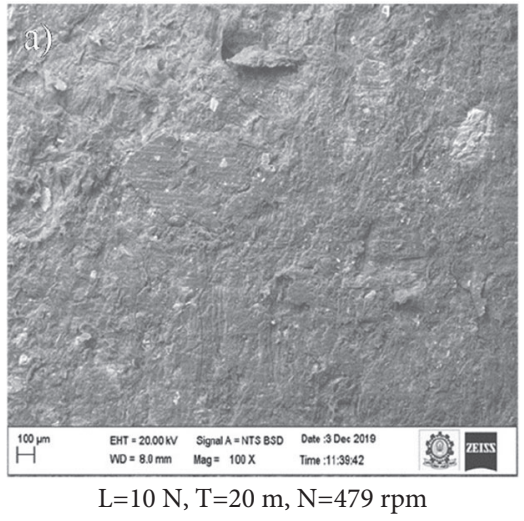

(a)

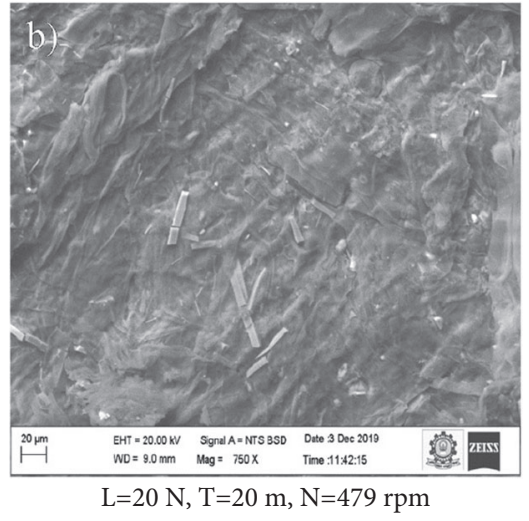

(b)

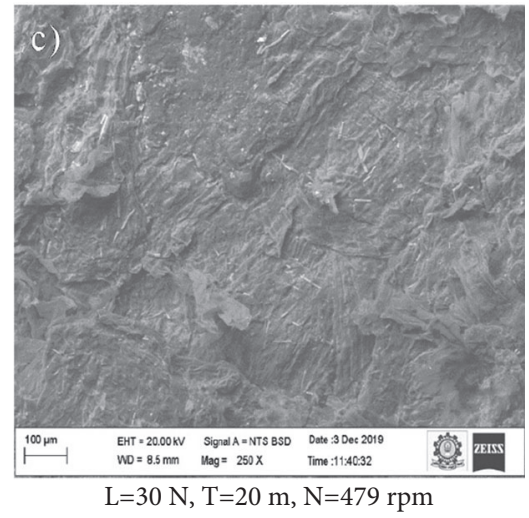

(c)

FIGURE 9: Electron image of water hyacinth composite material worn surface observed on the samples tested at different process conditions. (a) $L=10 \mathrm{~N}, T=20 \mathrm{~m}$, and $N=479 \mathrm{rpm}$. (b) $L=20 \mathrm{~N}, T=20 \mathrm{~m}$, and $N=479 \mathrm{rpm}$. (c) $L=30 \mathrm{~N}, T=20 \mathrm{~m}$, and $N=479 \mathrm{rpm}$.

transformation due to sliding particles are noticed [24]. From the observation of the wear experiment, the good interfacial locking between the fibre and matrix phase has led to the good wear performance of the natural composites. Wear surface of the test samples is shown in Figure 9.

Figure 9(a) displays a very close view of the scanning electron microscope images and the fibres pulled out during the matrix phase by showing so many holes. In Figure 9(b), the epoxy resin matrix phase bonding is clearly visible. There is strong interfacial bonding between fibre and epoxy resin matrix because of this. Composite performance was greatly affected by this bonding property. Figures 9(a)-9(c) illustrate that a load of $30 \mathrm{~N}$ applied over a period of 20 minutes has higher friction than a load of $10 \mathrm{~N}$ applied over the same period. As the speeds decrease, the friction on the surfaces increases. Due to applied load, the materials are prone to high shear and led to a maximum surface damage [25-28]. Figures $10(\mathrm{a})-10(\mathrm{~d})$ show the different impact angles $\left(30^{\circ}\right.$, $45^{\circ}$, and $60^{\circ}$ ) as well as the erodent velocity and discharge rate along with each crack, cleavage pattern, angle impingement, and weave pattern on a crater surface with appropriate angles of impact. 


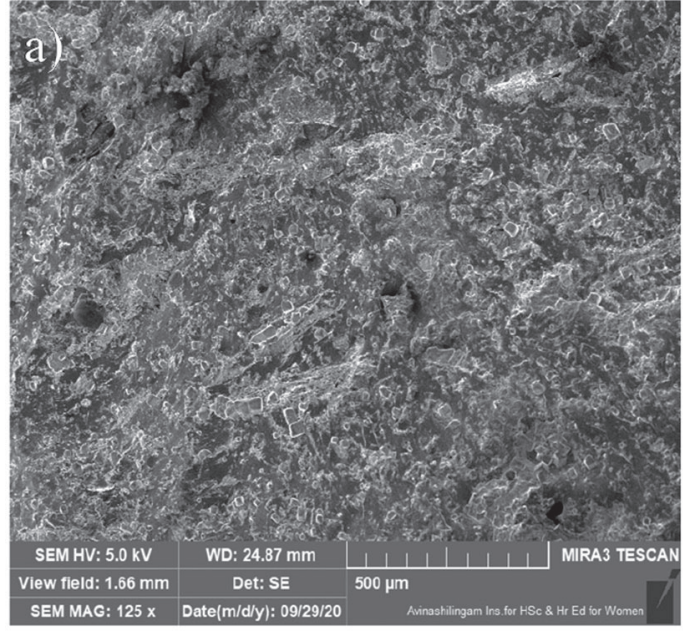

$\mathrm{IA}=30 ; \mathrm{EV}=28 ; \mathrm{DR}=2.5$

(a)

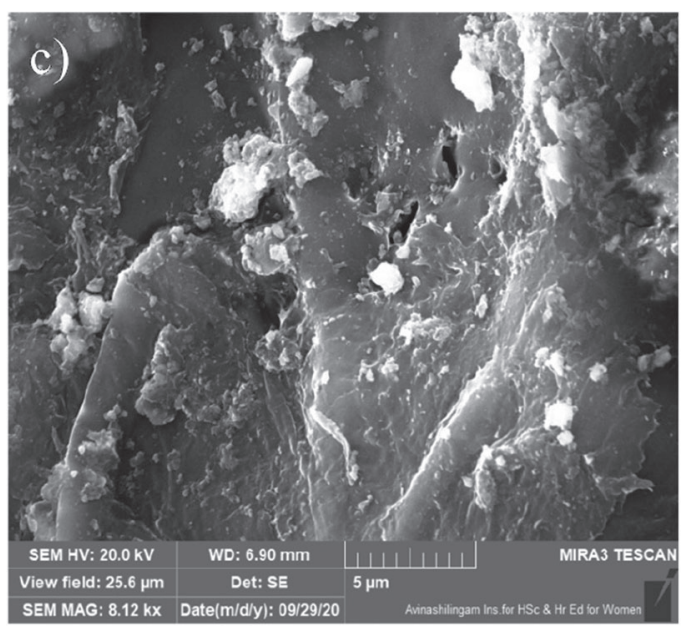

$\mathrm{IA}=60 ; \mathrm{EV}=28 ; \mathrm{DR}=2.5$

(c)

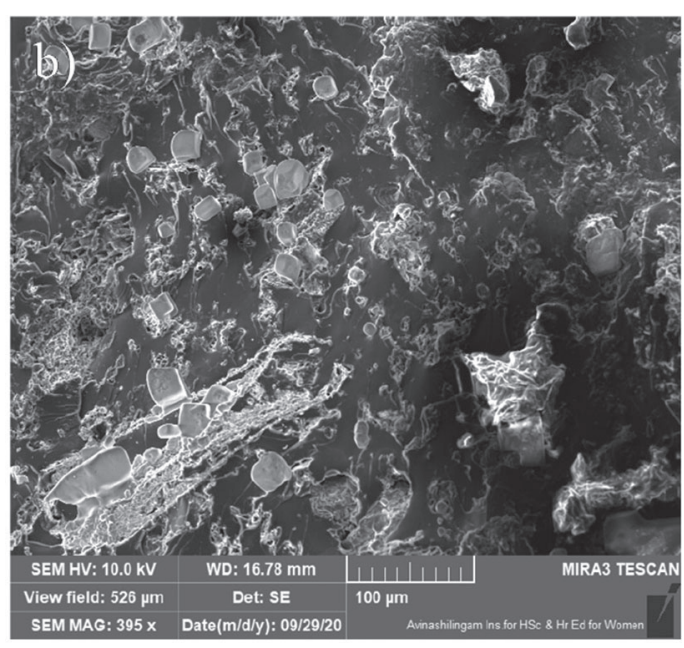

$\mathrm{IA}=45 ; \mathrm{EV}=28 ; \mathrm{DR}=2.5$

(b)

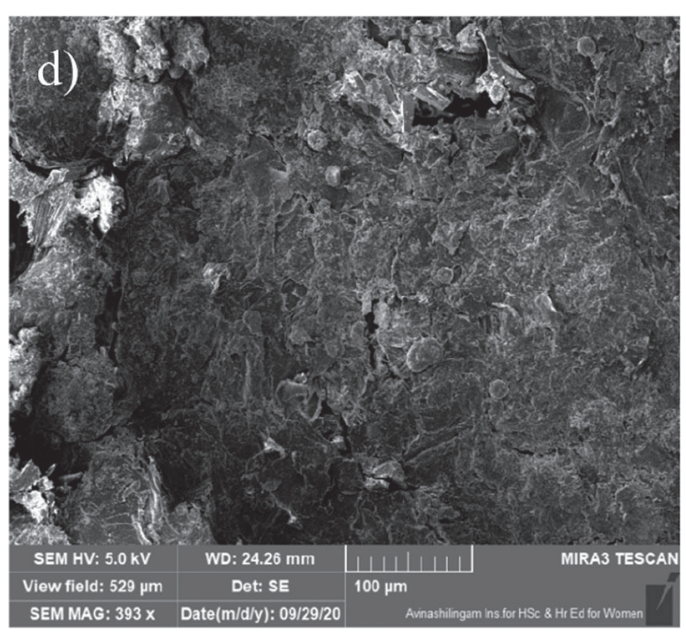

Crater Surface

(d)

FIGURE 10: Surface images of the erosion sample at various working conditions. (a) $\mathrm{IA}=30 ; \mathrm{EV}=28 ; \mathrm{DR}=2.5$. (b) $\mathrm{IA}=45 ; \mathrm{EV}=28 ; \mathrm{DR}=2.5$. (c) $\mathrm{IA}=60 ; \mathrm{EV}=28 ; \mathrm{DR}=2.5$. (d) Crater surface.

\section{Conclusion}

Compression moulding is used to prepare both dry sliding and erosion test specimens. The following conclusions are drawn from the wear test and erosion test of water hyacinth plant fibre composites:

(i) Water hyacinth natural fibre enhances the fibrematrix interfacial bonding with the respective percentage: $30>35>25>20>15$.

(ii) The volume loss of the hyacinth composite is reduced by $26 \%$.

(iii) When the nozzle angle is decreased simultaneously, the wear rate is increased.

(iv) From the analysis of variance, the influence of individual parameters is identified. Air jet erosion particle velocity has a maximum contribution of $58 \%$ towards surface wear followed by erodent discharge (20\%) and impact angle (11\%). Similarly, in sliding wear, the applied load has a maximum contribution followed by sliding velocity and sliding duration.

(v) The surface defect of the erosion test is to find out $45^{\circ}$, and the wear sample is highly affected at $30 \mathrm{~N}$ with $479 \mathrm{rpm}$ speed.

(vi) Fibre pullouts and surface fracture are the common failure observed through the scanning electron microscope.

\section{Data Availability}

No data were used to support this study. 


\section{Conflicts of Interest}

The authors declare that they have no conflicts of interest.

\section{References}

[1] V. Arumuga prabu, M. Uthayakumar, V. Manikandan, N. Rajini, and P. Jeyaraj, "Influence of redmud on the mechanical, damping and chemical resistance properties of banana/polyester hybrid composites," Materials \& Design, vol. 64, pp. 270-279, 2014.

[2] N. Rajini, J. W. Jappes, S. Rajakarunakaran, and P. Jeyaraj, "Dynamic mechanical analysis and free vibration behavior in chemical modifications of coconut sheath/nano-clay reinforced hybrid polyester composite," Journal of Composite Materials, vol. 47, no. 24, pp. 3105-3121, 2013.

[3] K. Balamurugan, M. Uthayakumar, M. Ramakrishna, and U. T. S. Pillai, "Air jet erosion studies on $\mathrm{Mg} / \mathrm{SiC}$ composite," Siliconindia, vol. 12, no. 2, pp. 413-423, 2020.

[4] E. SurojoE, Jamasri, V. Malau, and M. N. Ilman, "Effects of phenolic resin and fly ash on coefficient of friction of brake shoe composite," ARPN J Eng Appl Sci, vol. 9, pp. 2234-2240, 2014.

[5] A. Viswanath, H. Dieringa, K. K. Ajith Kumar, U. T. S. Pillai, and B. C. Pai, "Investigation on mechanical properties and creep behavior of stir cast AZ91-SiCp composites," Journal of Magnesium and Alloys, vol. 3, no. 1, pp. 16-22, 2015.

[6] M. Patel, D. Patel, S. Sekar, P. B. Tailor, and P. V. Ramana, "Study of solid particle erosion behaviour of SS 304 at room temperature," Procedia Technology, vol. 23, pp. 288-295, 2016.

[7] A. Karantzalis, "al- (Al9 Co2, Al13Co4) powder metallurgy processed composite materials: analysis of microstructure, sliding wear and aqueous corrosion," Mater Sci Eng with Adv Res, pp. 52-59, 2017.

[8] Z. Leman, S. M. Sapuan, M. Azwan, M. M. H. M. Ahmad, and M. A. aleque, "The effect of environmental treatments on fiber surface properties and tensile strength of sugar palm fiberreinforced epoxy composites," Polymer - Plastics Technology and Engineering, vol. 47, pp. 606-612, 2018.

[9] B. Rashid, Z. Leman, M. Jawaid, M. J. Ghazali, M. R. Ishak, and M. A. Abdelgnei, "Dry sliding wear behavior of untreated and treated sugar palm fiber filled phenolic composites using factorial technique," Wear, vol. 380-381, pp. 26-35, 2017.

[10] P. C. Verma, R. Ciudin, A. Bonfanti, P. Aswath, G. Straffelini, and S. Gialanella, "Role of the friction layer in the hightemperature pin-on-disc study of a brake material," Wear, vol. 346-347, pp. 56-65, 2016.

[11] M. S. Senthil Kumar, N. Mohana Sundara Raju, P. S. Sampath, and U. Vivek, "Tribological analysis of nano clay/epoxy/glass fiber by using Taguchi's technique," Materials \& Design, vol. 70, pp. 1-9, 2015.

[12] B. Shivamurthy, K. Murthy, P. C. Joseph, K. Rishi, K. U. Bhat, and S. Anandhan, "Mechanical properties and sliding wear behavior of jatropha seed cake waste/epoxy composites," Journal of Material Cycles and Waste Management, vol. 17, no. 1, pp. 144-156, 2015.

[13] T. G. Mamatha, A. Patnaik, S. Biswas, and P. Kumar, "Finite element modelling and development of SiC-filled ZA-27 alloy composites in erosive wear environment: a comparative analysis," Proceedings of the Institution of Mechanical Engineers - Part J: Journal of Engineering Tribology, vol. 225, no. 11, pp. 1106-1120, 2011.
[14] M. M. Khan and G. Dixit, "Abrasive wear characteristics of silicon carbide particle reinforced zinc based composite," Siliconindia, vol. 10, no. 4, pp. 1315-1327, 2018.

[15] M. A. Chowdhury, U. K. Debnath, D. M. Nuruzzaman, and M. M. Islam, "Experimental evaluation of erosion of gunmetal under asymmetrical shaped sand particle," Adv Tribo, vol. 2015, pp. 1-31, 2015.

[16] M. M. Khan and G. Dixit, "Evaluation of microstructure, mechanical, thermal and erosive wear behavior of aluminumbased composites," Siliconindia, vol. 12, no. 1, pp. 59-70, 2020.

[17] N. Sumrith and R. Dangtungee, "Mechanical properties of water hyacinth fiber reinforced bio-based epoxy composite," Key Engineering Materials, vol. 818, pp. 7-11, 2019.

[18] N. Flores Ramirez, Y. Sanchez Hernandez, J. Cruz de Leon, S. R. Vasquez Garcia, L. Domratcheva Lvova, and L. Garcia Gonzalez, "Composites from water hyacinth (Eichhornea crassipe) and polyester resin," Fibers and Polymers, vol. 16, no. 1, pp. 196-200, 2015.

[19] V. Karthikeyan, A. N. Balaji, and V. Vignesh, "Effect of rope mat and random orientation on mechanical and thermal properties of banana ribbon-reinforced polyester composites and its application," International Journal of Polymer Analysis and Characterization, vol. 21, no. 4, pp. 296-304, 2016.

[20] M. N. Norizan, K. Abdan, K. Abdan, M. S. Salit, and R. Mohamed, "Physical, mechanical and thermal properties of sugar palm yarn fibre loading on reinforced unsaturated polyester composite," Journal of Physical Science, vol. 28, no. 3, pp. 115-136, 2017.

[21] P. Gopal, S. Bordoloi, R. Ratnam et al., "Investigation of infiltration rate for soil - biochar composites of water," Acta Geophysica, vol. 67, no. 1, pp. 231-246, 2019.

[22] S. A. Ghani and B. Y. Lim, "Effect of treated and untreated filler loading on the mechanical, morphological, and water absorption properties of water hyacinth fibers- low density polyethylene composites," Applied Mechanics and Materials, vol. 679, pp. 184-188, 2009.

[23] A. Buasri, N. Chaiyut, T. Petsungwan, Y. Boonyuen, and S. Moonmanee, "Effect of surface treatment on interfacial and properties of water hyacinth fiber reinforced poly(lactic acid) composites," Advanced Materials Research, vol. 463-464, pp. 449-452, 2012.

[24] S. Chonsakorn and S. Srivorradatpaisan, "Effects of different extraction methods on some properties of water hyacinth fiber," Journal of Natural Fibers, vol. 16, no. 7, pp. 1015-1025, 2018.

[25] D. O. Okia, C. K. Ndiema, and M. S. Ahmed, "Physical and chemical properties of water hyacinth," Based Composite Briquettes, vol. IV, pp. 28-36, 2016.

[26] M. Karina, H. Onggo, and A. Syampurwadi, "Physical and mechanical properties of natural fibers filled polypropylene composites and its recycle," Journal of Biological Sciences, vol. 7, no. 2, pp. 393-396, 2007.

[27] M. Saha, H. Rahman, and A. Ali, "Effect of fibre loadings on mechanical properties of water hyacinth fibre reinforced poplypropylene composites," in Proceedings of the Int Conf Mech Eng Dhaka, pp. 18-20, Bangladesh, 2011.

[28] R. Melentiev and F. Fang, "Investigation of erosion temperature in micro-blasting," Wear, vol. 420-421, pp. 123-132, 2019. 